\title{
Nutrient density score of typical Indonesian foods and dietary formulation using linear programming
}

\author{
Ignasius Radix AP Jati ${ }^{1,2, *}$, Vellingiri Vadivel ${ }^{1}$, Donatus Nöhr ${ }^{1}$ and \\ Hans Konrad Biesalski ${ }^{1,2}$ \\ ${ }^{1}$ Institute of Biological Chemistry and Nutrition, University of Hohenheim, Garbenstrasse 30, D-70599 Stuttgart, \\ Germany: ${ }^{2}$ Food Security Center, University of Hohenheim, Stuttgart, Germany
}

Submitted 1 November 2011: Final revision received 14 March 2012: Accepted 15 March 2012: First published online 25 April 2012

\begin{abstract}
Objective: The present research aimed to analyse the nutrient density (ND), nutrient adequacy score (NAS) and energy density (ED) of Indonesian foods and to formulate a balanced diet using linear programming.

Design: Data on typical Indonesian diets were obtained from the Indonesian SocioEconomic Survey 2008. ND was investigated for 122 Indonesian foods. NAS was calculated for single nutrients such as Fe, Zn and vitamin A. Correlation analysis was performed between ND and ED, as well as between monthly expenditure class and food consumption pattern in Indonesia. Linear programming calculations were performed using the software POM-QM for Windows version 3.

Setting: Republic of Indonesia, 2008.

Subjects: Public households ( $n$ 68800).

Results: Vegetables had the highest ND of the food groups, followed by animalbased foods, fruits and staple foods. Based on NAS, the top ten food items for each food group were identified. Most of the staple foods had high ED and contributed towards daily energy fulfillment, followed by animal-based foods, vegetables and fruits. Commodities with high ND tended to have low ED. Linear programming could be used to formulate a balanced diet. In contrast to staple foods, purchases of fruit, vegetables and animal-based foods increased with the rise of monthly expenditure.

Conclusions: People should select food items based on ND and NAS to alleviate micronutrient deficiencies in Indonesia. Dietary formulation calculated using linear programming to achieve RDA levels for micronutrients could be recommended for different age groups of the Indonesian population.
\end{abstract}

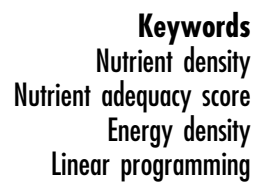

One of the largest nutritional problems in developing countries is micronutrient deficiency ${ }^{(1)}$. Severe micronutrient malnutrition can lead to various diseases, stunted growth and blindness, especially in children ${ }^{(2)}$. Micronutrient deficiencies are usually not perceived by poor and illiterate populations. Therefore such deficiency status is called 'hidden hunger' because the effects cannot be seen or felt at any one particular time. It means that even though people eat food every day and do not feel hungry, micronutrient deficiency could occur if the intake of foods lacks the necessary micronutrients ${ }^{(3)}$.

Indonesians suffer from micronutrient deficiency, especially of $\mathrm{Fe}, \mathrm{Zn}$ and vitamin $\mathrm{A}^{(4)}$. A study in West Java among 155 children revealed that the incidence of Fe and vitamin A deficiency was $54 \%$ and $57 \%$, respectively ${ }^{(5)}$. The prevalence of $Z n$ deficiency in pregnant women was $49 \%$, while it was $27 \%$ in lactating women ${ }^{(6)}$. The primary causes of micronutrient deficiency are poor diet quality compounded by lack of sanitation, hygiene and disease control. Unbalanced proportions of staple foods, vegetables, fruits and animal-based foods in a typical Indonesian diet are believed to play an important role in the deficiency condition. Among the staple foods, white rice has the highest proportion in the diet (54\%). Indonesians consume $102 \mathrm{~kg}$ white rice/capita per annum and very low amounts of vegetables, fruits and animal-based foods, which are actually rich sources of micronutrients ${ }^{(7)}$.

Micronutrient deficiency in Indonesia can be improved by food-based approaches through dietary diversity ${ }^{(8)}$. This can be achieved by formulating a balanced diet using locally available and culturally acceptable Indonesian foods. The nutrient adequacy score (NAS) and nutrient density (ND) approaches can assist implementation of the dietary diversity strategy through calculation of the nutritional contents of foods ${ }^{(0,10)}$. Meanwhile, linear programming (LP) can be used as one technique to formulate a balanced diet. 
Even though the nutritional values of common Indonesian foods have been reported in the past, there have been no attempts to select the foods with high micronutrient density. Hence, the objectives of the present research were to estimate the ND, NAS and energy density (ED) of Indonesian foods and, based on the outcomes, to make recommendations concerning the formulation of traditional diets using LP with regard to Fe, Zn, vitamin A and fulfilment of energy requirements. Further, the influence of household budget on the food consumption pattern was also investigated in the study.

\section{Methods}

Data from the 2008 Indonesian Socio-Economic Survey of commonly consumed Indonesian foods (122 foods), which contains information on 68800 public households and monthly expenditure class, were used. Food composition data for each food were obtained from the Indonesian Food Composition Table, which consists of 971 foods divided into twenty-four categories ${ }^{(11)}$. The database of commonly consumed foods was then divided into four categories: staple foods (cereals and tubers), fruits, vegetables (including legumes) and animal-based foods.

$\mathrm{ND}$ is defined as the ratio of the nutrient composition of a food to the nutrient requirements of an individual. $\mathrm{ND}$ is one of the tools useful to consumers for choosing nutrient-dense foods in a healthy diet. Foods that contain substantial amounts of key nutrients and have a relatively low energy content are considered nutrient-dense foods ${ }^{(12)}$. The original formula of ND was developed as naturally nutrient rich score based on $8368 \mathrm{~kJ}(2000 \mathrm{kcal})$ of foods and as NAS based on $100 \mathrm{~g}$ of foods ${ }^{(10,12)}$. In the present study ND was calculated by dividing the NAS by the ED of the food as expressed in the following formula $^{(10)}$

$$
\begin{aligned}
\mathrm{ND}= & \left(\left\{\left[\Sigma\left(\text { nutrient }_{i} / \mathrm{RDA}_{i}\right) \times 100\right] / 7\right\}\right. \\
& / \text { energy provided }) \times 100,
\end{aligned}
$$

where RDA is based on the dietary reference intake. In the present research seven micronutrients $(\mathrm{Fe}, \mathrm{Zn}, \mathrm{Ca}, \mathrm{P}$, vitamin $\mathrm{A}$, thiamin and vitamin $\mathrm{C}$ ) were considered ${ }^{(13)}$. The RDA values for the seven nutrients are shown in Table 1. The higher the ND score calculated using the above formula, the more nutrient dense is the food. NAS was calculated using the following formula by addressing single nutrients (Fe, Zn and vitamin A) to investigate the contribution (\%) of each food in consideration of their deficiencies in Indonesia:

$$
\mathrm{NAS}=(\mathrm{Fe}|\mathrm{Zn}| \operatorname{vitamin} \mathrm{A}) / \mathrm{RDA} .
$$

The results of NAS are provided only for ten foods in each food group having higher values. The conversion factor
Table 1 List of seven nutrients used for calculation of nutrient density and nutrient adequacy score

\begin{tabular}{lr}
\hline Nutrient & RDA \\
\hline Fe $(\mathrm{mg})$ & 13 \\
Zn (mg) & 11 \\
Vitamin A ( $\mu \mathrm{g}$ RE) & 800 \\
Ca $(\mathrm{mg})$ & 800 \\
P (mg) & 600 \\
Thiamin (mg) & 1 \\
Vitamin C (mg) & 75 \\
\hline
\end{tabular}

RDA, Indonesian recommended dietary allowance (Departemen Kesehatan ${ }^{(13)}$ ); $\mathrm{RE}$, retinol equivalents.

1:12 was used for pro-vitamin A to retinol equivalents $(\mathrm{RE})^{(14)}$.

ED was calculated as the amount of available energy per unit weight of food ( $\mathrm{kJ} / 100 \mathrm{~g}$ edible portion). Correlation analysis was then carried out to explore the relationships between ND and ED.

Four food groups (staple foods, vegetables, side dishes (animal-based foods), fruits) were used for LP calculation. White rice, sweet potato and cassava were chosen for the staples food group. Ten foods of each group with high ND were chosen from vegetables, fruits and animal-based food groups. The average amount of micronutrient with regard to the proportion of each food consumed daily in the dietary profile of food groups was used for the nutrient profiling. LP was performed using an opensource version of the computer program POM-QM for Windows version 3 (Pearson Education/Prentice Hall). The objective function of the LP was to minimize the amount of food consumed in the diet and express it as a linear function of individual food weights as described in the formula:

$$
Y=a_{0}+a_{1} \cdot X_{1}+a_{2} \cdot X_{2}+\ldots+a_{n} \cdot X_{n}
$$

where $a_{0}=0$, while $a_{1}, a_{2}, \ldots, a_{n}$ are constants and $X_{1}$, $X_{2}, \ldots, X_{n}$ are the individual food weights. Furthermore, nutritional constraints were established to guarantee that the nutrition exceeds or at least equals the RDA. Constraints can be expressed by following formula:

$$
b_{1} \cdot X_{1}+b_{2} \cdot X_{2}+\ldots+b_{n} \cdot X_{n}(=;>; \geq ;<; \leq) C
$$

where $b_{1}, b_{2}, \ldots, b_{n}$ are the constant constraint values of $X$ and $C$ is the constraint value determined. The nutritional constraints used for this research were energy, $\mathrm{Fe}, \mathrm{Zn}$ and vitamin A requirements based on age group. The consumption constraints were determined in order to obtain a realistic diet. The nutritional and consumption constraints used for LP are shown in Table 2. Sweet potato and cassava, which had high ND for staple foods, were included in the diet formulation. However, liver was excluded from the calculation in order to avoid inflation of the nutrient value of animal-based food groups. 
Table 2 Nutritional and consumption constraints of the linear programming for different age groups, Indonesia

\begin{tabular}{|c|c|c|c|c|c|c|c|c|c|c|}
\hline Age group (years) & Energy (kJ) & Iron (mg) & Zinc (mg) & Vit $A(R E)$ & Rice (g) & Csv (g) & $\mathrm{Sp}(\mathrm{g})$ & Veg (g) & $\mathrm{SD}(\mathrm{g})$ & Fruits (g) \\
\hline $4-6$ & $\geq 6489.54$ & $\geq 9$ & $\geq 9 \cdot 7$ & $\geq 450$ & $\leq 300$ & $\leq 50$ & $\leq 50$ & $\geq 200$ & $=200$ & $=200$ \\
\hline $7-9$ & $\geq 7536 \cdot 24$ & $\geq 10$ & $\geq 11 \cdot 2$ & $\geq 500$ & $\leq 300$ & $\leq 50$ & $\leq 50$ & $\geq 200$ & $=200$ & $=100$ \\
\hline Male, $10-12$ & $\geq 8582.94$ & $\geq 13$ & $\geq 14.0$ & $\geq 600$ & $\leq 350$ & $\geq 50$ & $\geq 50$ & $=200$ & $=200$ & $=100$ \\
\hline Male, 13-15 & $\geq 10048 \cdot 32$ & $\geq 19$ & $\geq 17 \cdot 4$ & $\geq 600$ & $\leq 400$ & $=75$ & $=75$ & $\geq 200$ & $\geq 250$ & $\geq 100$ \\
\hline Male, 16-18 & $\geq 10885.68$ & $\geq 15$ & $\geq 17 \cdot 0$ & $\geq 600$ & $\leq 450$ & $=75$ & $=75$ & $\geq 200$ & $\geq 250$ & $\geq 100$ \\
\hline Male, 19-29 & $\geq 10676.34$ & $\geq 13$ & $\geq 12 \cdot 1$ & $\geq 600$ & $\leq 450$ & $=75$ & $=75$ & $\geq 200$ & $\geq 250$ & $\geq 200$ \\
\hline Male, 30-49 & $\geq 9838.98$ & $\geq 13$ & $\geq 13 \cdot 4$ & $\geq 600$ & $\leq 450$ & $=75$ & $=75$ & $\geq 200$ & $\geq 250$ & $\geq 200$ \\
\hline Female, $10-12$ & $\geq 8582.94$ & $\geq 20$ & $\geq 12 \cdot 6$ & $\geq 600$ & $\leq 350$ & $\geq 50$ & $\geq 50$ & $=300$ & $=200$ & $=100$ \\
\hline Female, $13-15$ & $\geq 9838.98$ & $\geq 26$ & $\geq 15 \cdot 4$ & $\geq 600$ & $\leq 400$ & $=75$ & $=75$ & $\geq 200$ & $=350$ & $\geq 100$ \\
\hline Female, 16-18 & $\geq 9210 \cdot 96$ & $\geq 26$ & $\geq 14 \cdot 0$ & $\geq 600$ & $\leq 450$ & $=45$ & $=75$ & $\geq 200$ & $\geq 250$ & $\geq 100$ \\
\hline Female, 19-29 & $\geq 10676 \cdot 34$ & $\geq 13$ & $\geq 12 \cdot 1$ & $\geq 600$ & $\leq 450$ & $=75$ & $=75$ & $\geq 200$ & $\geq 250$ & $\geq 200$ \\
\hline Female, 30-49 & $\geq 7536 \cdot 24$ & $\geq 26$ & $\geq 9 \cdot 8$ & $\geq 500$ & $\leq 300$ & $=50$ & $=50$ & $\geq 200$ & $\geq 200$ & $\geq 200$ \\
\hline
\end{tabular}

Vit A, vitamin A; Csv, cassava; Sp, sweet potato; Veg, vegetables; SD, side dishes (animal-based foods).

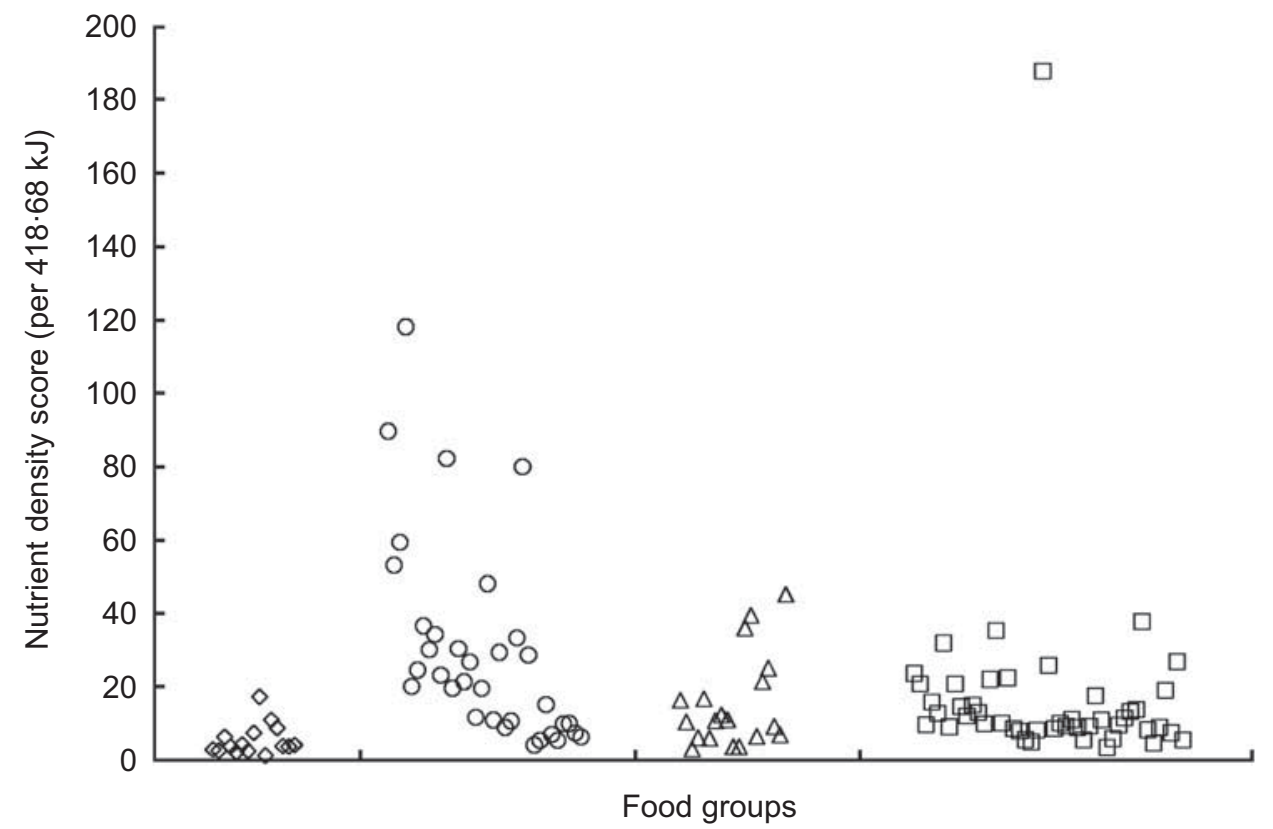

Fig. 1 Nutrient density score (per $418.6 \mathrm{~kJ} / 100 \mathrm{kcal}$ ) of commonly consumed Indonesian foods in different food groups $(\diamond$, staple foods, average $=5 \cdot 42 ; \mathrm{O}$, vegetables, average $=30 \cdot 03 ; \Delta$, fruits, average $=15 \cdot 29 ; \square$, animal-based foods, average $=17 \cdot 34$ )

The relationship between monthly expenditure categories and purchased food groups was analysed to provide a brief description of the influence of economic status on the food consumption pattern in Indonesia.

Microsoft ${ }^{\circledR}$ Excel and SPSS version 12 were used for calculation and statistical analysis. Ethical approval was not required.

\section{Results}

Among the food groups, vegetables had on average the highest ND, followed by animal-based foods, fruits and staple foods (Fig. 1). Based on NAS calculation, the top ten food items in each category with respect to micronutrients are presented in Table 3 . The results show that white rice, being a commonly consumed commodity in Indonesia, is a poor source of micronutrients and exhibited an NAS value of $7 \cdot 7 \%$ of $\mathrm{Fe}, 4.9 \%$ of $\mathrm{Zn}$ and $0 \%$ of vitamin $\mathrm{A}$.

The calculation of ED revealed that most but not all of the staple foods are highly energy dense (between 1400 and $1600 \mathrm{~kJ} / 100 \mathrm{~g}$; Fig. 2). In the vegetables group, legumes had higher ED compared with other foods. For animalbased foods there was variation in the ED levels. Fruits had the lowest ED compared with the other food groups (Fig. 2). Figure 3 reveals the relationship between ND and ED of foods. Food commodities with high ND tended to have low ED. Correlation analysis showed a negative relationship between ND and ED in all four food categories.

Table 4 provides the results of LP calculation. The inclusion of cassava and sweet potato in the diet could 
Table 3 Nutrient adequacy score for iron, zinc and vitamin A of the top ten food items in each food category, Indonesia

\begin{tabular}{|c|c|c|c|c|c|c|c|}
\hline \multicolumn{8}{|c|}{$\mathrm{Fe}$} \\
\hline Staple foods & $\%$ & Vegetables & $\%$ & Fruits & $\%$ & Animal-based foods & $\%$ \\
\hline Fresh corn (yellow) & $17 \cdot 7$ & Spinach & $30 \cdot 8$ & Salacca & $30 \cdot 8$ & Liver & $100 \cdot 0$ \\
\hline Corn rice & $15 \cdot 4$ & Tempeh & $30 \cdot 8$ & Spanish plum & $23 \cdot 1$ & Innards excl. liver & $61 \cdot 5$ \\
\hline Corn flour & $15 \cdot 4$ & Tofu & $30 \cdot 8$ & Mango & $15 \cdot 4$ & Anchovies & $30 \cdot 8$ \\
\hline Sago flour & $15 \cdot 4$ & Red kidney bean & $28 \cdot 5$ & Papaya & $15 \cdot 4$ & Canned fish & $30 \cdot 8$ \\
\hline Dried cassava & $15 \cdot 4$ & Soybean & $26 \cdot 2$ & Avocado & $7 \cdot 7$ & Canned meat & $30 \cdot 8$ \\
\hline Cassava flour & 8.5 & Swamp cabbage & $23 \cdot 1$ & Rambutan & $7 \cdot 7$ & Local chicken egg & $25 \cdot 4$ \\
\hline Rice & $7 \cdot 7$ & Chinese cabbage & $23 \cdot 1$ & Lanzon & $7 \cdot 7$ & Shrimp & $23 \cdot 8$ \\
\hline Glutinous rice & $7 \cdot 7$ & Cayenne pepper & $23 \cdot 1$ & Durian & $7 \cdot 7$ & Cockle/snail & $23 \cdot 1$ \\
\hline Rice flour & $7 \cdot 7$ & Peanuts with shell & $19 \cdot 2$ & 'Ambon' banana & $7 \cdot 7$ & Mackerel & $23 \cdot 1$ \\
\hline Wheat flour & $7 \cdot 7$ & Cassava leaf & $15 \cdot 4$ & 'Raja' banana & $7 \cdot 7$ & Skipjack tuna & $23 \cdot 1$ \\
\hline \multicolumn{8}{|c|}{$\mathrm{Zn}$} \\
\hline Staple foods & $\%$ & Vegetables & $\%$ & Fruits & $\%$ & Animal-based foods & $\%$ \\
\hline Dried cassava & $56 \cdot 7$ & Cassava leaf & $40 \cdot 6$ & Durian & $5 \cdot 5$ & Dried beef & $59 \cdot 1$ \\
\hline Flour dried cassava & $51 \cdot 2$ & Swamp cabbage & $19 \cdot 5$ & Avocado & $5 \cdot 3$ & Canned meat & $56 \cdot 7$ \\
\hline Cassava & $50 \cdot 4$ & Soyabean & $9 \cdot 1$ & Jack fruit & $3 \cdot 3$ & Shredded fried meat & $50 \cdot 4$ \\
\hline Cassava flour & $47 \cdot 3$ & Beans & $8 \cdot 8$ & Spanish plum & 1.9 & Beef & $43 \cdot 3$ \\
\hline Taro & $42 \cdot 5$ & Mushroom & $6 \cdot 3$ & Rose-apple & $1 \cdot 8$ & Trimming & $35 \cdot 4$ \\
\hline Glutinous rice & $11 \cdot 8$ & Spinach & $4 \cdot 2$ & 'Ambon' banana & $1 \cdot 6$ & Lamb meat & 33.9 \\
\hline Wheat flour & $9 \cdot 5$ & Mustard greens & $3 \cdot 3$ & 'Raja' banana & $1 \cdot 6$ & Buffalo meat & $33 \cdot 1$ \\
\hline Rice & $5 \cdot 0$ & Young jackfruit & $3 \cdot 3$ & Sapodilla & $1 \cdot 6$ & Pork & $33 \cdot 1$ \\
\hline Fresh corn (yellow) & $4 \cdot 9$ & Mungbeans & $3 \cdot 3$ & Tomato & $1 \cdot 4$ & Cheese & $33 \cdot 1$ \\
\hline Rice flour & $4 \cdot 7$ & Squash & $3 \cdot 1$ & Rambutan & $1 \cdot 3$ & Shrimp & $31 \cdot 5$ \\
\hline \multicolumn{8}{|c|}{ Vitamin A } \\
\hline Staple foods & $\%$ & Vegetables & $\%$ & Fruits & $\%$ & Animal-based foods & $\%$ \\
\hline Sweet potatoes & $98 \cdot 4$ & Carrot & $86 \cdot 3$ & Salacca & $31 \cdot 2$ & Liver & 1750 \\
\hline Fresh corn (yellow) & $34 \cdot 6$ & Cayenne pepper & $66 \cdot 1$ & Jack fruit & $24 \cdot 0$ & Innards excl. liver & $87 \cdot 5$ \\
\hline Cassava & $6 \cdot 1$ & Spinach & $58 \cdot 6$ & Mango & $12 \cdot 1$ & Quail egg & $43 \cdot 8$ \\
\hline Dried cassava & $4 \cdot 3$ & Chillies red & $35 \cdot 1$ & Rose-apple & $10 \cdot 3$ & Preserved milk & $38 \cdot 8$ \\
\hline Flour dried cassava & $3 \cdot 2$ & Green chilli & $21 \cdot 2$ & Durian & $9 \cdot 4$ & Canned powder milk & $38 \cdot 8$ \\
\hline Cassava flour & $1 \cdot 6$ & Swamp cabbage & $8 \cdot 3$ & Tomato & $4 \cdot 7$ & Skipjack tuna preserved & $33 \cdot 8$ \\
\hline Corn flour & $1 \cdot 3$ & String bean & $4 \cdot 4$ & Sapodilla & $3 \cdot 7$ & Skipjack tuna & $33 \cdot 8$ \\
\hline Corn rice & $0 \cdot 7$ & Young jackfruit & $3 \cdot 8$ & Watermelon & $3 \cdot 2$ & Fresh milk & $31 \cdot 3$ \\
\hline Taro & 0.5 & Mustard greens & $2 \cdot 4$ & Papaya & $2 \cdot 9$ & Snake head & $25 \cdot 0$ \\
\hline Glutinous rice & 0.03 & Petai beans & $1 \cdot 9$ & Spanish plum & $2 \cdot 1$ & Yellow tail & $24 \cdot 0$ \\
\hline
\end{tabular}

decrease the white rice intake in the diet. Formulations of a balanced diet with regard to $\mathrm{Fe}, \mathrm{Zn}$, vitamin $\mathrm{A}$ and energy fulfillment are presented based on different sex/age groups.

Figure 4 shows the relationship between monthly expenditure class of households and purchased food categories. There were positive correlations between monthly expenditure and purchased amounts of fruits, vegetables and animal-based foods. On the other hand, monthly food expenditure was negatively correlated with the amount of staple foods purchased.

\section{Discussion}

According to Fig. 1, vegetables and fruits could be potential sources of micronutrients as long as their intake increases. Green leafy vegetables such as green cabbage, spinach and cassava leaves had higher ND among the vegetables group. Another vegetable with high ND was green chilli. These green leafy vegetables are common in the Indonesian diet; however the amounts consumed are not sufficient to fulfill micronutrient requirements. Among the fruits, tomato, apple and papaya were the ones with high ND. However fruits are not consumed by Indonesians on a daily basis, and therefore their contribution to the RDA is limited. On the other hand, staple foods had the lowest ND. An exception was found for sweet potato, which had a high ND score (17.9). This is because sweet potato is a rich source of pro-vitamin A and its energy level is not as high as that of other staple foods. This finding is consistent with previous reports which stated that fruits and vegetables have higher ND compared with staple foods such as grains and starchy foods ${ }^{(12,15,16)}$. The concept of ND score could become an important tool to help Indonesian people choose nutrient-dense foods to fulfill their micronutrient requirements. Nevertheless, a standard reference for ND 


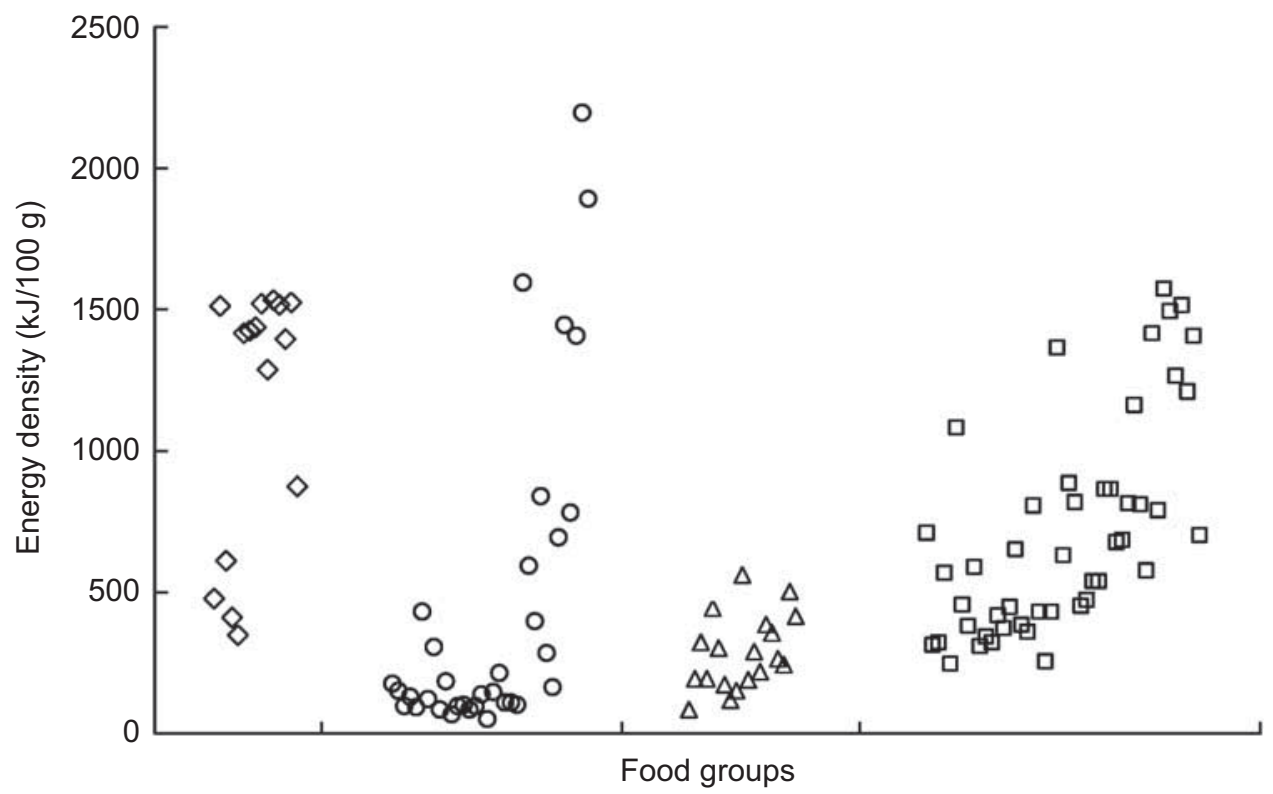

Fig. 2 Energy density score $(\mathrm{kJ} / 100 \mathrm{~g})$ of commonly consumed Indonesian foods in different food groups ( $\diamond$, staple foods, average $=1151 \cdot 71 ;$ o, vegetables, average $=452 \cdot 21 ; \Delta$, fruits, average $=283 \cdot 99 ; \square$, animal-based foods, average $=718 \cdot 89$ )

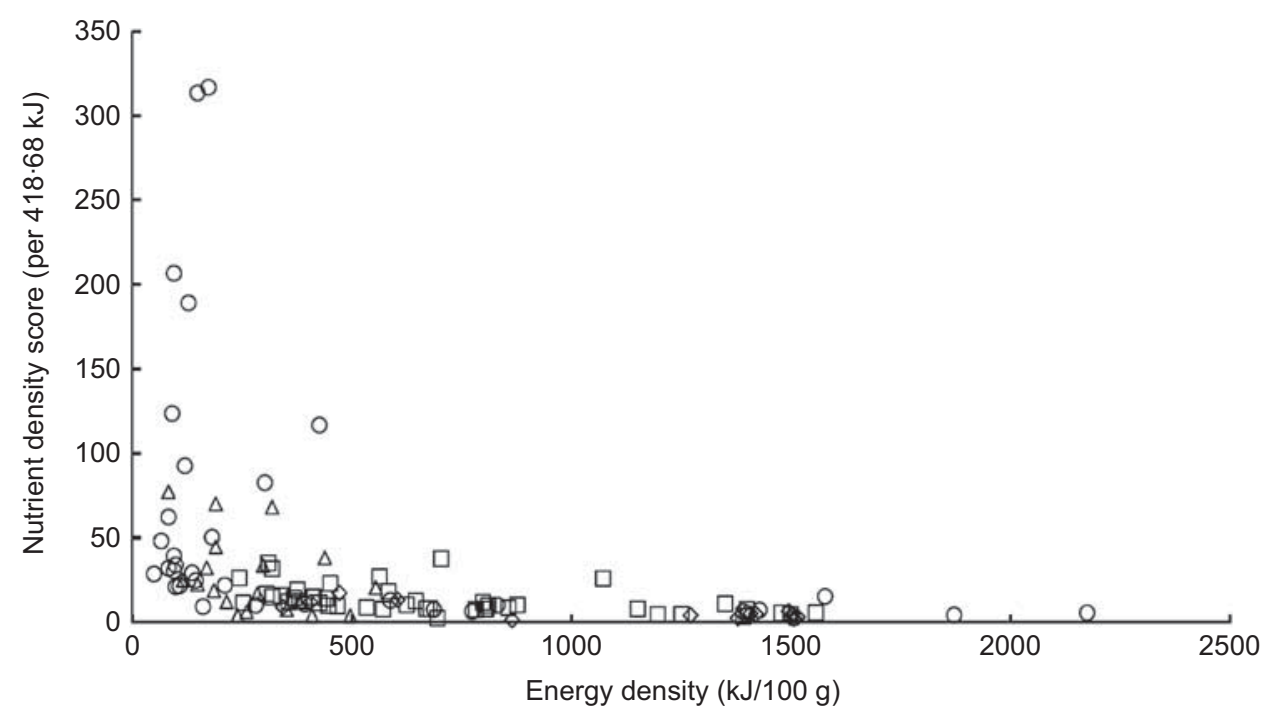

Fig. 3 Relationship between nutrient density score and energy density of commonly consumed Indonesian foods in different food groups $(\diamond$, staple foods, correlation $=-0.7397$; $O$, vegetables, correlation $=-0.4536 ; \Delta$, fruits, correlation $=-0 \cdot 6132$; $\square$, animalbased foods, correlation $=-0 \cdot 1272$

score classification is needed in order to have comprehensive information about the ND of foods. We can then, for instance, make a comparison among foods regarding those that have high, medium or low ND.

NAS is a traditional way of evaluating the nutritional adequacy of diets based on comparison of nutrient intake with the RDA. Although NAS is not as comprehensive as $\mathrm{ND}$, it is a valuable tool for diet recommendations, especially to address a single nutrient requirement. For example to increase Fe intake, foods such as corn and cassava are recommended as substitutes for white rice as the major staple food in the Indonesian diet. For the vegetables group, spinach, tempeh and tofu are proposed. Fruits are not a rich source of $\mathrm{Zn}$ and therefore the NAS values were relatively low. Animal-based foods can contribute to fulfill 31.5 to $59 \cdot 1 \%$ of the $\mathrm{Zn}$ requirement, according to NAS results. However the cost of animalbased foods is relatively high and hence not affordable by economically weaker sections of the population. Liver could also be the answer for both $\mathrm{Fe}$ and vitamin A deficiencies, but there is a misconception that eating animal organs including liver is unhealthy. Therefore, 
Table 4 Diet formulation using linear programming for different age groups, Indonesia

\begin{tabular}{llccccc}
\hline Age group (years) & Rice $(\mathrm{g})$ & Csv $(\mathrm{g})$ & $\mathrm{Sp}(\mathrm{g})$ & Veg $(\mathrm{g})$ & SD $(\mathrm{g})$ & Fruits $(\mathrm{g})$ \\
\hline $4-6$ & $296 \cdot 25$ & 0 & 50 & $54 \cdot 07$ & 200 & 200 \\
$7-9$ & 300 & 50 & 50 & $497 \cdot 62$ & 100 & 200 \\
Male, 10-12 & 350 & $181 \cdot 51$ & 50 & 200 & 100 & 200 \\
Male, 13-15 & 400 & 75 & 75 & 200 & $135 \cdot 73$ & $368 \cdot 11$ \\
Male, 16-18 & 450 & 75 & 75 & 200 & 100 & $382 \cdot 94$ \\
Male, 19-29 & 450 & 75 & 75 & 200 & 200 & 340 \\
Male, 30-49 & $437 \cdot 16$ & 75 & 75 & 200 & 200 & 250 \\
Female, 10-12 & $315 \cdot 32$ & $239 \cdot 68$ & 50 & 300 & 100 & 200 \\
Female, 13-15 & $395 \cdot 92$ & 75 & 75 & 200 & $117 \cdot 04$ & 350 \\
Female, 16-18 & $391 \cdot 47$ & 45 & 75 & 200 & 100 & $299 \cdot 43$ \\
Female, 19-29 & 450 & 75 & 75 & 200 & 200 & 340 \\
Female, 30-49 & $272 \cdot 64$ & 50 & 50 & 200 & 200 & $318 \cdot 91$ \\
\hline
\end{tabular}

Csv, cassava; Sp, sweet potato; Veg, vegetables; SD, side dishes (animal-based foods).

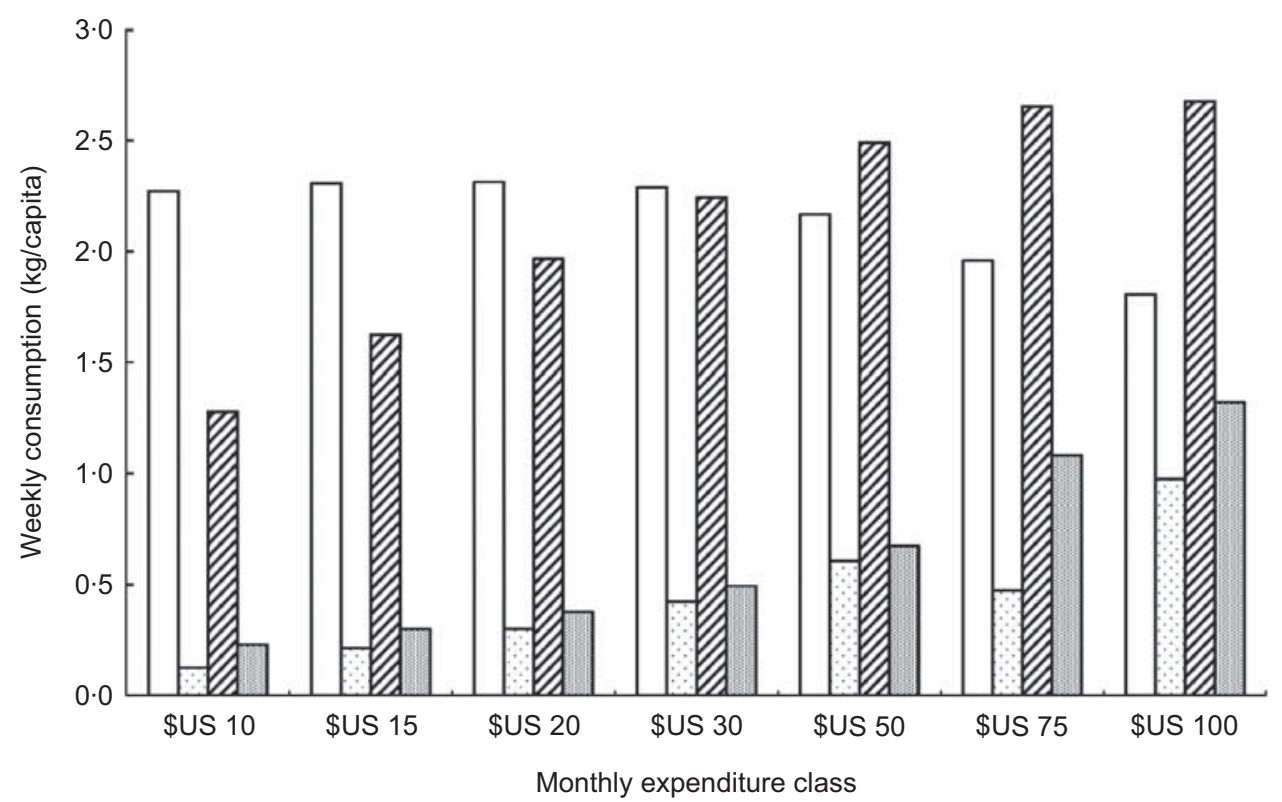

Fig. 4 Relationship between monthly expenditure class and purchased food categories in Indonesia $(\square$, staple foods, correlation $=$ -0.9726 ; , animal-based foods, correlation $=0.9148 ; \mathbb{Z}$, vegetables, correlation $=0.8718$; 國, fruits, correlation $=0.9971$ )

such misbelief should be dispelled and liver should be included as a part of the daily diet. The challenges to fulfill the RDA of Fe, $\mathrm{Zn}$ and vitamin A can be overcome by including those high NAS foods in the regular diet of Indonesians. However, addressing single nutrients became the limitation of this concept because people need several micronutrients, and some of the micronutrients work synergistically ${ }^{(17)}$.

Information on the ED values of Indonesia's commonly consumed foods can be seen in Fig. 2. Most of the staple foods have high ED and they contribute to daily energy fulfillment, followed by animal-based foods, vegetables and fruits. A similar result was reported on the ED of different food groups ${ }^{(16)}$. Among vegetables, legumes have higher ED which contributes more energy than rice and other staple foods. In addition, legumes also possess high amounts of micronutrients. Therefore several studies recommended legumes as a healthy food ingredient in the daily diet ${ }^{(18-21)}$.

ND and ED were negatively correlated for all food groups (Fig. 3). This result indicated that high-ED foods tended to be nutrient poor. The more micronutrientdense foods are those which have high contents of micronutrients and contribute low amounts of energy. Therefore such foods should be prioritized to be included in the daily diet to fulfill micronutrient requirements without exceeding the energy supplied. The present result is in line with previous findings on the relationship between ND and ED of foods ${ }^{(12)}$.

The LP was designed to minimize the quantity (grams) of food consumed, which is more appropriate for Indonesia because the prices of the food groups (except for animalbased foods) are similar. A number of Indonesian people are producing and consuming their own vegetables, 
chicken and fish. Therefore information on the minimum amount of food to be consumed is more crucial as an objective function than to minimize the price. The result of formulation of a balanced diet using LP revealed that cassava and sweet potato can be used as partial substitutes for white rice in the diet. Cassava can contribute to the $\mathrm{Zn}$ requirement while sweet potato can supply a high amount of pro-vitamin A. Fe, Zn and vitamin A sources such as spinach, swamp cabbage and cassava leaves should be included in the diet because they can be eaten in large quantities without an overload of energy. The modification of side dishes can be formulated to get more variation of the diet. Based on the proposed diet formulation, different age groups can fulfill their micronutrient requirements along with energy consideration (Table 4). LP is a simple tool to calculate a balanced diet ${ }^{(22)}$. The limitation of LP calculation in the present study was due to the fact that the data could not be presented as individual formulation because there were a lot of simulations made, therefore the average of the top ten foods having high ND and commonly consumed foods were used for nutrient profiling.

The relationship between monthly expenditure and food consumption pattern is illustrated in Fig. 4. Households with low monthly expenditure (\$US 10) spent $58 \%$ of the expenditure towards the purchase of staple foods $(2 \cdot 2 \mathrm{~kg} /$ week $)$, but with an increase of monthly expenditure there was a decrease in the purchase of staple foods. The highest monthly expenditure class (\$US 100) spent only $27 \%$ on staple foods $(1 \cdot 3 \mathrm{~kg} /$ week). As opposed to the purchase of staple foods, the purchase of fruits, vegetables and animal-based foods increased with the rise in monthly expenditure. This finding is in line with previous research which postulated that food budget constraints preferentially orient food choices towards energy-dense foods that are low in micronutrients ${ }^{(22-25)}$. As food prices rise, the items that drop out of the diet are vegetables and fruits, followed by animal-based foods ${ }^{(26,27)}$. Therefore, low-income people tend to purchase high-ED foods in the form of staple foods. However, it is still debatable whether the low cost of staple foods is the main reason for such a pattern in Indonesia, because unlike animal-based foods, the costs of vegetables and fruits were similar to those of staple foods ${ }^{(28)}$. The influence of cultural factors could also be one aspect responsible for this condition.

The aggravated condition of $\mathrm{Fe}, \mathrm{Zn}$ and vitamin A deficiencies in Indonesia might also be due to the interaction among micronutrients. Deficiency in one micronutrient could lead to shortage of other micronutrients. For example, $\mathrm{Zn}$ deficiency could lead to vitamin A deficiency because $\mathrm{Zn}$ is involved in the synthesis of retinol-binding protein, which transports retinol to the tissues and also protects tissues from the potential toxicity of retinol. $\mathrm{Zn}$ also plays a role in the synthesis of alcohol dehydrogenase, a microsomal enzyme that could convert retinol into retinal and help release retinyl palmitate, a storage form of retinol in the liver ${ }^{(29-33)}$. Deficiency of vitamin A could also have a negative impact on Fe level in the body and vice versa.

\section{Conclusions}

ND, ED and NAS are important tools for consumers in planning their daily diet in order to meet nutritional requirements. If ND and NAS were included in nutrition education (e.g. by demonstrating food patterns with a high ND/NAS) they could help to alleviate micronutrient deficiencies and as a consequence reduce related diseases. Based on the relationship between ND and ED, people can control their energy intake levels. Dietary formulation calculated using LP to achieve RDA levels of micronutrients could be recommended for different age groups of Indonesians. Even though monthly expenditure level has an influence on food consumption patterns, Indonesians should prepare their daily diet based on the household income with regard to ND, NAS and ED. They can select alternative and economically feasible food items based on their ability to purchase and fulfill micronutrient and energy requirements. For future study, inclusion of food prices in the LP model could be considered.

\section{Acknowledgements}

This research was supported by the Dr Hermann Eiselen PhD Grant from the Foundation Fiat Panis as a part of the doctoral thesis of I.R.A.P.J. supported by the German Academic Exchange Service (DAAD)/Food Security Center scholarship programme. The authors declare no conflict of interest. I.R.A.P.J. contributed towards data analyses and interpretation and led the writing; V.V. helped interpret the results and in writing of the paper; D.N. helped interpret the results and provided critical feedback on drafts of the article; H.K.B. was involved in developing the initial idea, helped interpret the results and provided critical feedback on drafts of the article. The authors acknowledge Badan Pusat StatistikStatistics Indonesia (BPS), Republic of Indonesia, for the data collection.

\section{References}

1. World Health Organization (2002) World Health Report 2002. Geneva: WHO.

2. Food and Agriculture Organization of the United Nations (2004) The State of Food Insecurity in the World 2004. Rome: FAO

3. Allen L, de Benoist B, Dary O et al. (editors) (2006) Guidelines on Food Fortification with Micronutrients. Geneva: WHO/FAO.

4. Kurniawan A (2002) Policies in alleviating micronutrient deficiencies: Indonesia's experience. Asia Pac J Clin Nutr 11, Suppl., S360-S370.

5. Helen Keller International (1998) Re-emergence of the threat of vitamin A deficiency. Indonesia Crisis Bulletin Year 1, Issue 2. Jakarta: HKI. 
6. Dijkhuizen MA, Wieringa FT, West CE et al. (2001) Concurrent micronutrient deficiencies in lactating mothers and their infants in Indonesia. Am J Clin Nutr 73, 786-791.

7. Badan Pusat Statistik-Statistics Indonesia (2008) National Socio Economic Survey 2008. Jakarta: BPS.

8. Thompson B (2011) Combating iron deficiency: foodbased approaches. In Combating Micronutrient Deficiencies: Food-Based Approaches, pp. 268-288 [B Thompson and L Amoroso, editors]. Wallingford: CABI Publishing.

9. Hansen RG, Wyse BW \& Sorenson AW (1979) Nutrition Quality Index of Food. Westport, CT: AVI Publishing Co.

10. Drewnowski A (2005) Concept of a nutritious food: toward a nutrient density score. Am J Clin Nutr 82, 721-732.

11. Badan Ketahanan Pangan (2004) Indonesian Food Composition Table. Jakarta: Indonesian Ministry of Agriculture.

12. Darmon N, Darmon M, Maillot M et al. (2005) A nutrient density standard for vegetables and fruits: nutrients per calorie and nutrients per unit cost. J Am Diet Assoc 105, 1881-1887.

13. Departemen Kesehatan (2004) Table of Recommended Dietary Allowance for Indonesians. Jakarta: Indonesian Ministry of Health.

14. Strobel M, Tintz J \& Biesalski HK (2007) The importance of $\beta$-carotene as a source of vitamin A with special regard to pregnant and breastfeeding women. Eur J Nutr 46, Suppl. 1, I/1-I/20.

15. Maillot M, Darmon N, Darmon M et al. (2007) Nutrientdense food groups have high energy cost: an econometric approach to nutrient profiling. J. Nutr 137, 1815-1820

16. Connel CL, Zoellner JM, Yadrick K et al. (2011) Energy density, nutrient adequacy, and cost per serving can provide insight into food choices in the Lower Mississippi Delta. J Nutr Educ Behav (In the Press); available at http:// dx.doi.org/10.1016/j.jneb.2011.02.003

17. Rahman MM, Wahed MA, Fuchs GJ et al. (2002) Synergistic effect of zinc and vitamin A on the biochemical indexes of vitamin A nutrition in children. Am J Clin Nutr 75, 92-98.

18. Geil PB \& Anderson JW (1994) Nutrition and health implications of dry beans: a review. I Am Coll Nutr 13, 549-558.

19. Kushi KH, Meyer KA \& Jacobs DR Jr (1999) Cereals, legumes, and chronic disease risk reduction: evidence from epidemiologic studies. Am J Clin Nutr 70, 3 Suppl., 451S-458S

20. Anderson JW, Smith BM \& Gustafson NJ (1994) Health benefits and practical aspects of high-fiber diets. Am J Clin Nutr 59, 5 Suppl., 1242S-1247S.
21. Messina MJ (1999) Legumes and soybeans: overview of their nutritional profiles and health effects. Am J Clin Nutr 70, 3 Suppl., 451S-458S.

22. Darmon N, Ferguson EL \& Briend A (2002) A cost constraint alone has adverse effects on food selection and nutrient density: an analysis of human diets by linear programming. J Nutr 132, 3764-3771.

23. Dibsdall LA, Lambert N, Bobbin RF et al. (2003) Lowincome consumers' attitudes and behaviour towards access, availability and motivation to eat fruit and vegetables. Public Health Nutr 6, 159-168.

24. Giskes K, Turrell G, Patterson C et al. (2002) Socioeconomic differences in fruit and vegetable consumption among Australian adolescents and adults. Public Health Nutr 5, 663-669.

25. Darmon N, Ferguson E \& Briend A (2003) Do economic constraints encourage the selection of energy dense diets? Appetite 41, 315-322.

26. Townsend MS, Aaron GJ, Monsivais P et al. (2009) Lessenergy-dense diets of low-income women in California are associated with higher energy-adjusted diet costs. $\mathrm{Am} \mathrm{J}$ Clin Nutr 89, 1220-1226.

27. Glanz K, Basil M, Maibach E et al. (1998) Why Americans eat what they do: taste, nutrition, cost, convenience, and weight control concerns as influences on food consumption. J Am Diet Assoc 98, 1118-1126.

28. Ministry of Agriculture (2011) Commodities pricelists updated March 15th, 2011. http://www.deptan.go.id (accessed March 2011).

29. Ekman M \& Reizenstein P (1993) Comparative absorption of ferrous and heme-iron with meals in normal and iron deficient subjects. Z Ernährungswiss 32, 67-70.

30. Roughead ZK, Zito CA \& Hunt JR (2002) Initial uptake and absorption of non heme iron and absorption of heme iron in humans are unaffected by the addition of calcium as cheese to a meal with high iron bioavailability. Am J Clin Nutr 76, 419-425.

31. Harvey LJ, Fairweather-Tait SJ, Fox TE et al. (2001) Methods for analysis of trace-element absorption. In Advances in Isotope Methods for the Analysis of Trace Elements in Man, pp. 59-80 [M Jackson and N Lowe, editors]. London: CRC Press.

32. Russell RM (2000) The vitamin A spectrum: from deficiency to toxicity. Am J Clin Nutr 71, 878-884.

33. Jang JT, Green JB, Beard JL et al. (2000) Kinetic analysis shows that iron deficiency decreases liver vitamin A mobilization in rats. J Nutr 130, 1291-1296. 